\title{
Ситникова О.А. \\ Некоторые особенности словообразования неологизмов в современном английском языке (на материале «языка» пандемии коронавируса)
}

Белгородский государственный национальный исследовательский университет (Россия, Белгород)

doi: 10.18411/lj-05-2021-281

\section{Аннотация}

Данная статья посвящена словообразовательной специфике неологизмов современного английского языка, появившихся в период пандемии коронавируса COVID19. В работе рассматриваются вопросы определения неологизма, причины создания и использования новых слов, ведущих способов образования новых единиц языка, а также наиболее продуктивные модели, по которым образованы неологизмы, связанные с пандемией коронавируса.

Ключевые слова: Неологизмы, аффиксация, конверсия, заимствование, сокращение, словосложение, словослияние.

\section{Abstract}

This article is devoted to the derivational specifics of the neologisms of the modern English language that appeared during the COVID19 coronavirus pandemic. The paper examines the definition of a neologism, the reasons for the creation and use of new words, the leading ways of forming new language units, as well as the most productive models by which neologisms associated with the coronavirus pandemic are formed.

Key words: Neologisms, affixation, conversion, borrowing, abbreviation, word composition, word fusion.

\section{Введение}

Изучая неологизмы нельзя не вспомнить слова В. фон Гумбольдта, который говорил, что язык народа есть его дух, и дух народа есть его язык, и трудно представить себе что-то более тождественное.( Избранные труды по языкознанию: С 36).

Перемены в общественном развитии неизбежно влекут за собой изменения в лексиконе. Как и во всех других языках, в английском языке постоянно происходит обновление словарного состава: слова устаревают, забываются и появляются новые неологизмы.

Вторая половина 20 века стала самым неогенным, т.е. породила наибольшее количество неологизмов в языке, именно так утверждали многие лингвисты в конце 20 века. Однако, приняв во внимания все события начала нового столетия, мы смело можем прогнозировать еще большую неогенность XXI века. Бурное развитие науки, информационных и телекоммуникационных технологий, постоянные изменения в экономической, общественной и политической жизни общества и усиление роли массовой культуры и спорта способствуют появлению новых единиц языка.

Потребность общества в выражении новых понятий, возникающих в результате развития всех общественных сфер жизни общества способствует созданию новых слов.

Британский лингвист Дж. Айто описывает процесс возникновения неологизмов следующим образом: «Каждый год, который проходит, подбрасывает новые идеи, опыт и изобретения, для которых до сих пор не существовало имени, и поскольку имена являются незаменимыми винтиками в механизме коммуникации, наша естественная человеческая склонность к их образованию вскоре заполняет большинство пробелов» (Ayto J. A Century of New Words: 2007).

Целью работы является изучить понятие “неологизм", рассмотреть основные причин возникновения неологизмов и способы их образования. 
Актуальность исследования обусловлена необходимостью дальнейшего изучения феномена неологизмов в современном английском языке и как способа пополнения словарного запаса языка, и как средства его развития во времени. Неологизмы также необходимо рассматривать и с точки зрения их социальной значимости, так как, изучая язык, мы изучаем общество и различные его сферы.

Объектом исследования являются неологизмы современного английского языка, появившиеся в период пандемии новой коронавирусной инфекции. Предметом исследования являются словообразовательные особенности данных неологизмов.

Впервые термин «неологизм» появился во французском языке, откуда был заимствован другими языками в значении «употребление или привычка употребления новых слов, инноваций в языке, а также новое слово или выражение» (Рублева 2004: 117). Традиционно в научных работах по лингвистике и филологии термином «неологизм» обозначают новые слова в разных языках народов мира. В последние десятилетия многие ученые в своих статьях раскрывали проблему определения понятия «неологизм». Однако на данный момент в современной лингвистике отсутствует единый подход к пониманию сущности вновь возникающих слов. Так, В.Г. Гак считает, что «неологизм - это новое слово, новое либо по форме, либо по содержанию, либо и по форме и по содержанию» (Заботкина 1989: С 67).

«Неологизм - это появившееся в языке слово или словосочетание», именно такое определение предлагает большой толковый словарь русского языка С.А. Кузнецова.(Кузнецова, 1998: С 630).

Более точное определение мы можем увидеть в Лингвистическом энциклопедическом словаре: «неологизм» - это слова, значения слов или словосочетания, появившиеся в определенный период в каком-либо языке или использованные один раз 13 («окказиональные» слова) в каком-либо тексте или акте речи. Принадлежность слов к неологизмам является свойством относительным и историчным. Неологизмы определяются также как слова, возникшие на памяти применяющего их поколения» (Котелова 1971: С 12).

Рассмотрев все понятия, можно сделать вывод, что главная особенность неологизмов состоит в том, что слово или значение является новым, и подразумевается, что новое слово за короткий промежуток времени может прочно войти в словарный состав языка или быть проигнорировано и вскоре забыто. Не все новые слова способны закрепиться в лексической структуре языка, так как продолжительность существования слов определяется тем, насколько велика и долговременна потребность в них.

Возникают неологизмы на базе уже имеющегося в языке материала, по установившимся словообразовательным моделям, т.е. применительно к уже существующей в языке системе средств и способов словообразования. Неологизмы не нарушают установившейся в языке традиции и не порождают резких изменений, так что даже люди разных поколений могут понимать друг друга.

Рассмотрим способы формирования новых слов в английском языке, так как целью нашей работы является исследование проблемы неологизмов и способов их образования. Обратимся к проблеме способов словообразования к которым лингвисты относят морфологические, синтаксические и лексико-семантические типы словообразования.

Под общим названием словообразование (word-building) объединяются очень различные способы обогащения словарного состава языка. Важнейшим из них является морфологический способ, при котором новые слова создаются путем сочетания морфем. Новое слово при этом оформляется и новым звуковым комплексом, т.е., точнее, новой комбинацией уже существовавших в языке элементов.

Еще в конце прошлого века к сильным неологизмам можно было отнести и заимствования. Однако в действительности это не самый главный способ обогащения 
словарного состава. Цифра 30\% характеризует число исконных слов в словаре, но совершенно не дает представления об их относительной употребительности и важности для коммуникации.

Традиционно выделяют три типа соединений: нейтральный, морфологический, синтаксический.

Аффиксация является одним из основных средств словообразования. Аффиксальное словопроизводство, или, как этот способ также называют, аффиксация или деривация, или просто слово-производство (derivation), т.е. создание новых слов путем при-соединения к основе тех или иных словообразовательных элементов аффиксов. (Cohort-ing - группа людей (врачи, учителя) потенциально восприимчивая к вирусной инфекции), (De-roning - дезинфицирование предметов). Новые неологизмы, которые образовались с помощью данного способа: coronator - человек, который выздоровел от коронавируса; covidian - человек, который носит маску и хирургические перчатки в своей машине, соблюдает социальную дистанцию в общественных местах; coronials - поколение, родившееся после декабря 2020 года в результате карантина.

Словосложение (composition) - очень древний и до сих пор продуктивный способ создания новых слов путем объединения двух или более основ в одно целое. Рассмотрим примеры новых неологизмов: elbow bump - дружеское приветствие локтями; selfisolation - самоизоляция; circuit breaker - фиксированный период времени, в течение которого людям не разрешается покидать свои дома или свободно путешествовать, с целью уменьшения распространения опасной болезни; lockdown - чрезвычайная ситуация, на протяжении которой людям не разрешается свободно входить и посещать общественные места; doomscrolling - поиск информации о болезни в социальных сетях; coronaspeck - лишний вес, набранный во время карантина; panicbuying - панически скупать продукты питания и товары первой необходимости.

Еще одним активным словообразовательным процессом в современном английском языке является словослияние (blending в английской терминологии). Словослиянием называется процесс соединения двух (или более) слов без учета их морфологической структуры и основанного большей частью на созвучии или благозвучии соединяемых частей. Некоторые лингвисты считают, что в словослиянии объединяются словосложение и аббревиация, так как соединяются два слова (как в словосложении), но эти два слова, как правило, усечены (как в аббревиации) [2. С. 52; 4. С. 69]. Примерами словослияния в английском языке являются: Coronacranky вспыльчивость в результате длительной изоляции; quaranqueens - женщины преуспевающие в уборке во время изоляции; coronawashing - корпорации или отдельные лица, пользующиеся преимуществами пандемии для продвижения своего товара или производства; ronavation - ремонт во время локдауна; SPENDEMIC - по словам экспертов Babbel, это слово было придумано The New York Post, оно относится к росту онлайн-покупок во время пандемии; coronadivorce - разводы зарегистрированные во время коронавируса; spendemic - резкое увеличение числа онлайн-покупок; coronacation - прекращение учебы или работы в связи с пандемией рассматривается как праздник; homeference - виртуальная конференция, на которой участники могут присутствовать удаленно ( из дома); lockstalgia - мысль о том, что люди буду скучать за работой и учебой из дома; walktail - прогулки на свежем воздухе во время карантина; coronacoma - много спать во время карантина и не иметь представления о событиях в мире; coronalit - литература созданная во время пандемии; covidiot - человек, который безответственно относится ко всем ограничениям.

Сокращение (shortening, abbreviation) тип словообразования, при котором исходное слово теряет один или несколько звуков. Данный способ был зафиксирован еще в 15 веке. С тех пор он становится все более и более продуктивным. Этот рост становится особенно заметным во многих европейских языках в 20-м веке, и общеизвестно, что это развитие особенно интенсивно в английском. 
Новые укороченные слова появляются постоянно: об этом свидетельствуют многочисленные неологизмы, например: Rona = the coronavirus; the pandy = the global pandemic.

Существует четыре вида сокращений: акронимы, аббревиатуры, слияния и усечения.

Среди неологизмов последних десятилетий намечается тенденция к увеличению единиц этого типа. По данным, полученным нами в результате анализа первого словаря Барнхарта, они составили $4,8 \%$ от общего числа неологизмов. Во втором словаре Барнхарта их число составило уже $8 \%$ от всей массы неологизмов. Среди них преобладают частичные слова-слитки, т.е. единицы, в которых соединяется один усеченный элемент и полная форма другого элемента. Наиболее продуктивен тип финального усечения первого компонента: Europlug (Europeanplug); sigaretiquette (sigarette, etiquette).

Особенностью усечений является их сниженная стилистическая окраска. Слова образованные данным типом характерны только для разговорной речи и для различных типов сленга (школьного, газетного, спортивного). Ярким примером усечений являются: Rona $=$ the coronavirus.

Среди сокращений очень популярны аббревиатуры и акронимы. Что касается аббревиатуры, можно сказать, что из-за тесной связи между устной и письменной формами языка иногда трудно отличить слова, образованные в устной речи, от графических сокращений. Вот несколько примеров аббревиатур: WFH = working (or work) from home (работать дома онлайн); PCSD = post-coronavirus stress disorder (посткоронавирусное стрессовое расстройство); $\mathrm{PPE}=$ personal protective equipment (маска, перчатки, антисептик); masklessness - неверие в пандемию, маски и остальные атрибуты коронавируса; ACV - жизнь до появления коронавируса, B.C.V после . Они все чаще используются в устной речи и широко применяются в неформальных разговорах.

B отличие от аббревиатур, акронимы произносятся как полные слова: SARS Severe acute respiratory syndrome coronavirus.

В синтаксических соединениях слова образуются из отрезков речи, сохраняя в своей структуре многочисленные следы синтагматических отношений, характерных для речи: articles, prepositions, adverbs, prepositions, as in "Shelter in place" - stay at home during the pandemic; ZOOM BOMBING - Этот термин относится к нежелательному присутствию человека в видеочате, как правило, в программе встречи Zoom; Zoom mullet - специальная прическа для онлайн встреч, она собранная спереди и по бокам, но растрепанная сзади; vaccine nationalism - конкуренция стран за открытие и производство антивирусной вакцины.

Таким образом, в результате проведенного исследования мы выяснили, что самым популярным и продуктивным способом словообразования является словослияние.

$$
* * *
$$

1. Заботкина В.И. Новая лексика современного английского языка. - М.: Высшая школа, 1989. - 126 c.

2. Избранные труды по языкознанию: Пер. с нем. / Общ. ред. Г.В. Ра- мишвили; Послесл. А.В. Гулыги и В.А. Звегинцева. - М.: ОАО ИГ «Прогресс», 2000. - 400 с.ISBN 5-01-004661-Х

3. Котелова Н.3. Теоретические аспекты лексикографического описания неологизмов / Н.З. Котелова // Советская лексикография. - СПб.: Нестор-История, 2015. - 276 с.

4. Ayto J. A Century of New Words. - Oxford: Oxford University Press, $2007-480$ p.

5. Лексикология русского языка: Учеб. пособие для фи-лол. фак.ун-тов.-2-е изд., испр. и доп.-М.: Высш. шк., 1989.216 с.

6. Розен Е.В. Новое в лексике немецкого языка. - М.: Просвещение, 1976. - 174 с.

7. Рублева О. В. Лексикология современного русского языка: учебное пособие. - Владивосток: ТИДОТ ДВГУ, 2004. - $257 \mathrm{c}$.

8. https://www.collinsdictionary.com/us/dictionary/english/elbow-bump

9. https://dictionary.cambridge.org/ru/словарь/английский/elbow-bump 